\title{
Os Três Quartetos de Cordas de Alberto Nepomuceno
}

ANDERSON ROCHA

O cultivo da música de câmara instrumental no Brasil desenvolveuse especialmente nas últimas décadas do século XIX, com o crescente interesse do público pelo repertório das escolas românticas alemã e francesa. Até então, a ópera italiana era o gênero que monopolizava a vida musical dos principais centros brasileiros e, naturalmente, a música tocada nos seus salões refletia esta preferência. Os programas eram compostos basicamente por trechos populares de óperas, peças curtas e fantasias instrumentais que se prestavam, sobretudo, à exibição de virtuosismo dos intérpretes.

Uma nova tendência surge a partir da difusão dos clubes musicais, que passam a oferecer à elite social da época um maior número de concertos de câmara, além de conferências sobre assuntos literários e outros temas ligados à cultura. Luís Heitor Corrêa de Azevedo observa que, com os clubes, "a moda dos concertos clássicos ganhara a sociedade. O velho repertório 'filisteu', com seus fogos de artifício de bravura, cedia lugar à música de câmara e às partituras dos grandes mestres germânicos"1.

A mais bem-sucedida experiência no gênero ocorreu no Rio de Janeiro com o Club Beethoven. Fundado em 1882 por Robert Jope Kinsman Benjamin (1853-1927), violinista, compositor, regente e crítico musical, o Club Beethoven respondeu pela promoção de cento e trinta e seis con-

1. Luís Heitor Corrêa de Azevedo, Música no Tempo desta Casa, Rio de Janeiro, Casa do Estudante do Brasil, 1953, p. 55. 
certos de câmara, quatro grandes concertos sinfônicos e cinco vesperais. Nos sete anos em que esteve em atividade, a entidade manteve em seus quadros um quarteto de cordas permanente (do qual fazia parte o próprio Kinsman Benjamin) e contou também com uma academia de música e uma biblioteca, dirigida pelo escritor Machado de Assis (1839-1908) ${ }^{2}$.

Os reflexos deste novo gosto são notados na criação musical brasileira através da iniciativa pioneira de seus compositores, ao construir um repertório camerístico baseado em novos parâmetros. São adotadas técnicas de composição mais sofisticadas, se comparadas aos exemplos anteriores, tanto nos gêneros de morfologia curta quanto nas grandes formas. Este maior preparo ocorreu também em função das oportunidades oferecidas aos músicos de prosseguir sua formação no Velho Mundo, fazendo com que a afluência a esses centros de educação musical constituísse "fenômeno fundamental para a formação de compositores nascidos no século passado"3. Tais esforços resultaram num dos principais resultados criativos de uma geração de músicos que, nas palavras de Mário de Andrade, "já apresentavam uma técnica suficientemente forte para que a nossa música alimentasse umas primeiras aspirações de caminhar por si"'.

Essas mudanças se fizeram sentir também em relação à ampliação do repertório local. Até o ano de 1889, data da composição da primeira obra de Nepomuceno para quarteto de cordas, anotamos apenas quatro peças escritas para a formação: o Quarteto (s. d.) do padre José Joaquim Pereira da Veiga (1772-1840), o Quarteto (s. d.) de Damião Barbosa de Araújo (1778-1856), o Quarteto em lá menor (1885) de Sant'Ana Gomes e o Quarteto (1885) de Alexandre Levy5.

2. Vincenzo Cernicchiaro, Storia della Musica nel Brasile dai Tempi Coloniali Sino ai Nostri Giorni (1549-1925), Milano, Ed. Fratelli Riccioni, 1926, p. 550.

3. Maria Alice Volpe, "Compositores Românticos Brasileiros: Estudos na Europa". Revista Brasileira de Música, EM - UFRJ, vol. 21, 1994-1995, p. 51.

4. Mário de Andrade, Aspectos da Música Brasileira, São Paulo, Martins, 1975, p. 23.

5. Quanto ao "Quarteto" obrigado sobre motivo de D. Juan, de Mozart, atribuído ao compositor Manuel José Gomes (1792-1868), trata-se de um quinteto para cordas sem qualquer evidência de que seja do autor mencionado. (Lenita W. M. Nogueira, Museu Carlos Gomes. Catálogo de Manuscritos Musicais. São Paulo, Arte e Ciência, 1997, p. 355). Ver também Maria Alice Volpe, "Período Romântico Brasileiro: Alguns 
Em 1920, ano da morte de Alberto Nepomuceno, o número salta para vinte e sete composições. Até este momento, também fazem parte a Sonata para quarteto ou quinteto de cordas, 1894, de Antônio Carlos Gomes (1836-1896), mais dois quartetos de Santana Gomes (escritos em 1896 e 1905, respectivamente) e as obras de Otávio Meneleu Campos (1872-1927): o Quarteto em Sol maior, 1899; Quarteto em Lá maior, 1899; o Quarteto em Ré maior, 1901 e o Quarteto em Mi maior, 19011902. Das obras que Henrique Oswald (1852-1931) compôs para a formação, o quarteto opus 16 (s. d.) foi escrito provavelmente antes da década de 1910, sendo que os quartetos opus 39 e 46 surgiram posteriormente a esta fase. Glauco Velásquez (1884-1914) compôs a Suíte $n^{\circ} 1$ para quarteto de cordas em 1905 e o Primeiro Quarteto em 1910. Heitor Vila-Lobos (1887-1959) escreveu, até 1920, a Suíte Graciosa para dois violinos, viola e violoncelo, 1915; o Quarteto $n^{\circ} 1$, 1915; o Quarteto $n^{\circ}$ 2, 1915; o Quarteto $n^{\circ} 3$, 1916; o Quarteto $n^{\circ} 4,1917$. Também fazem parte deste período o Quarteto de João Otaviano Gonçalves (1892-1962), estreado em 1914; o Quarteto, 1917, de Paulino Chaves (1883-1948) e as peças de Francisco Braga (1868-1945): Visões, 1903 e Bendegó para Quarteto de Cordas, 1920, além das três obras do compositor cearense ${ }^{6}$.

Com efeito, a prática da música de câmara no Brasil viveu mudanças sensíveis, nas últimas décadas do século XIX, não apenas no que se refere à ampliação deste repertório. Foram estabelecidos novos parâmetros também nos campos do estilo, temática, influências e técnicas de composição, cujos aspectos merecem estudo pormenorizado, levandose em consideração o conjunto das condições materiais e ideais que envolvem sua criação. Entendemos que apenas o conhecimento baseado em tais parâmetros contribuirá positivamente para os desdobramentos da atual tendência de reavaliação dos diversos períodos e vertentes da música de concerto produzida no Brasil.

Os Quartetos de Cordas de Alberto Nepomuceno foram escritos entre 1889 e 1891 e tiveram como referencial mais direto a música do Ro-

Aspectos da Produção Camerística". Revista Música. São Paulo, Departamento de Música - ECA, USP, 1994, vol. 5, n² 2, pp. 137-138.

6. Enciclopédia da Música Brasileira, "Registro de Músicas". São Paulo, Art Editora, 1977, pp. 895-1159. 
mantismo alemão, corrente que significou, em seu contexto, verdadeira alternativa de "modernização" na música brasileira. Tratam-se de composições da sua juventude - pertencentes ao período de estudos na Europa - que fizeram parte dos trabalhos exigidos pelos seus professores daquela fase. É justo supor que, ao compor os quartetos, Nepomuceno tenha encontrado no repertório cultivado no Club Beethoven uma de suas grandes motivações, já que o autor fez parte da agremiação carioca, como pianista e professor, de 1885 a 1888 . Em determinadas situações, essas mesmas obras evidenciam também a intenção do autor em adaptar elementos da cultura popular nacional ao idioma musical por ele adotado, reunindo assim as duas temáticas presentes na sua trajetória de compositor: a nacional e universal.

\section{Quarteto $\mathbf{n}^{0} \mathbf{1}$, em Si menor}

Esta sua primeira abordagem mais ambiciosa do gênero camerístico foi concluída em Roma, no ano de 1889, quando realizava estudos na Academia Santa Cecilia. Neste período, Nepomuceno freqüentou as classes de harmonia e composição ministradas por Eugenio Terziani (18241889) - o mesmo regente responsável pela estréia da ópera Il Guarany de Carlos Gomes no Teatro La Scala de Milão - e Cesare de Sanctis (1830-1915), além do curso de piano com Giovanni Sgambatti (18411914). As experiências anteriores no terreno da escrita de câmara limitaram-se à composição de quatro peças para violoncelo e piano: Mazurca, 1887; Prière, 1887; Romance, 1889; Tarantela, 1889; Un soneto del Dante - Tanto gentile tanto onesta, para canto, violino e piano (1889); além de uma versão para quinteto de cordas da mesma Prière, de $1887^{7}$.

O estilo basicamente adotado, juntamente com uma hábil e equilibrada estruturação do discurso dos quatro instrumentos solistas, fazem desta peça o mais "clássico" dentre os três quartetos. Trata-se da mesma referência a modelos do passado musical da Europa central encontrada em outras obras de Nepomuceno, como a Suite Antique para piano solo (posteriormente transcrita para orquestra de cordas) e a Sonata para piano em fá menor, ambas compostas em 1893.

7. Sergio Alvim Correa, Alberto Nepomuceno: Catálogo Geral, Rio de Janeiro, Funarte, 1996, pp. 41-49. 
Pelo que se sabe até o momento, a primeira audição do Quarteto em si menor ocorreu somente no dia 18 de maio de 1933, treze anos após a morte do compositor. A estréia teve como palco o Instituto Nacional de Música, no Rio de Janeiro, com a interpretação do Quarteto Chiafitelli.

\section{Quarteto $\mathbf{n}^{0}$ 2, em Sol menor}

Embora o catálogo geral do compositor mencione a data e local de composição do seu segundo quarteto de cordas como sendo 1890, em Roma, pelo menos duas fontes autógrafas indicam com segurança o ano de 1891, quando Nepomuceno já se encontrava na capital do Império Alemão, sob a orientação de Heinrich von Herzogenberg (1843-1900). Das obras concluídas nesta fase inicial de estudos na Akademische Meister Schule de Berlim, também fazem parte um Adagio para cordas (1891) e as peças para piano solo intituladas Folhas d'Album n 1, 2 e 3 $(1891)^{9}$.

O Quarteto $\mathrm{n}^{\circ} 2$ é o mais extenso dos três exemplos para esta formação e um dos primeiros trabalhos realizados sob a orientação do mestre alemão. A preferência pelos tons menores, uma constante em sua obra, é outra característica aqui presente. Através de seu desenho tonal, é possível perceber a intenção do autor de estabelecer uma unidade de estrutura que vai além dos movimentos individuais, situando-os próximos à tonalidade principal (com os dois andamentos externos em sol menor e os internos na tonalidade da subdominante e da dominante do tom homônimo, respectivamente).

Desta obra foram preservadas três diferentes versões autógrafas, sendo uma delas um esboço do primeiro movimento apenas. Por conta das referidas diferenças entre manuscritos, chegou-se a apontar equivocadamente a existência de mais uma composição para quarteto de cordas: o Quarteto em sol menor Opus 6, com a data de composição fixada em 1889. De acordo com as nossas pesquisas, confirmadas em entrevista por Sérgio Alvim Corrêa, uma das versões manuscritas do segundo quarteto foi equivocadamente identificada como esta peça à parte. A classificação "Opus 6" está grafada apenas no manuscrito pertencente à

8. Idem, p. 43.

9. Idem, pp. 41-44. 
Biblioteca Nacional (MS/ N-IV-40), tratando-se, inclusive, de uma das partituras completas do Quarteto $\mathrm{n}^{\circ} 2$ (com quatro movimentos). Um outro erro encontrado nas principais obras de referência, a reforçar essa tese, diz respeito à tonalidade do Quarteto $\mathrm{n}^{\circ} 2$. Consta, inclusive no catálogo geral do compositor, como mi bemol maior, sendo a tonalidade de sol menor a informação correta (a mesma indicada para esta suposta "quarta" peça).

Segundo o que se sabe até o presente momento, apenas um dos andamentos do segundo quarteto de cordas foi executado em público quando o compositor ainda era vivo. Em fevereiro de 1902, Alberto Nepomuceno apresentou-se à frente de uma orquestra de cordas no $C l u b$ dos Diários em Petrópolis, estreando o segundo movimento que, também nesta versão isolada, recebeu o mesmo título. No Catálogo Geral, Sérgio Alvim Corrêa relaciona a versão para orquestra de cordas do Andante espressivo como uma obra avulsa e estabelece, como data e local de composição, o ano de 1896, em Petrópolis ${ }^{10}$.

\section{Quarteto n $^{0}$ 3, em Ré menor}

Foi também no ano de 1891 que Nepomuceno escreveu seu terceiro quarteto de cordas. Neste período, o autor estabeleceu alguns dos mais importantes contatos da sua fase de formação musical. Viajou para Viena, a fim de aperfeiçoar-se ao piano com renomado pianista polonês Theodor Lechetitzky (1830-1915), e assistiu a concertos regidos por Johannes Brahms (1833-1897) e Hans von Bülow (1830-1894); teve a oportunidade de vivenciar, desta forma, o ambiente onde desenrolou-se o célebre embate estético entre os adeptos da chamada música do futuro (preconizada pelos seguidores de Wagner e Liszt) e os partidários do compositor Johannes Brahms, tendências estas que influenciaram fortemente a sua música.

$\mathrm{O}$ Quarteto $\mathrm{n}^{\circ} 3$ destaca-se dos demais pela maior independência e complexidade técnica conferida às quatro partes instrumentais, tanto pelo caráter concertante do movimento inicial, quanto pelo jogo polifônico apresentado na série de variações do segundo andamento. $\mathrm{O}$ espírito brejeiro do terceiro movimento é mais evidenciado na sua ver-

10. Idem, p. 44. 
são orquestral, onde foram acrescentados alguns contracantos na seção das madeiras, além de novas modulações e uma coda mais extensa. Mesmo assim, permanece na versão para quarteto de cordas a mesma referência nativa, através das figuras pontuadas e de síncopas que o próprio autor classificou como um "ritmo de lundu" de sua época.

O subtítulo "brasileiro" do Quarteto em ré menor foi dado por Sérgio Alvim Corrêa, neto do compositor, que transcreveu estes mesmos quartetos de cordas, na década de 1960. Segundo Alvim Corrêa, trata-se do "primeiro trabalho camerístico brasileiro a apresentar uma bem definida temática nativista"11. A designação ocorreu em virtude da utilização pelo autor do terceiro movimento do Quarteto, o Intermezzo, na sua famosa suíte orquestral de 1891, a "Série Brasileira”, que é considerada pela historiografia brasileira um dos principais marcos da orientação nacionalista na nossa música. O Intermezzo, na sua versão orquestral, teve a sua estréia no Rio de Janeiro em 27 de outubro de 1895, três meses após o término de sua estada para estudos na Europa. O concerto aconteceu no Cassino Fluminense e teve como regente o próprio autor. $\mathrm{Na}$ ocasião, Nepomuceno teceu comentários acerca do emprego de ritmos populares no Intermezzo, através de texto contido no programa do referido concerto, que foi reproduzido por Oscar Guanabarino em artigo d' O Paiz. Nele, Nepomuceno descreve o segundo tema como "uma melodia característica, de um ritmo de lundu brasileiro, acompanhada por um motivo característico no quarteto [no caso as cordas da orquestra], que faz lembrar os nossos fadinhos"12. É importante ressaltar que tal intenção, de traduzir para sua música a riqueza das manifestações populares, acontece dois anos antes do encontro com o compositor norueguês Edward Grieg (1843-1907), apontado como o principal responsável por sedimentar no compositor cearense a convicção pela música nacionalista.

11. Sergio Alvim Correa, Texto do encarte do LP Alberto Nepomuceno: Música de Câmara do Brasil - Documentos da Música Brasileira, vol. 7, Quarteto de Cordas da Rádio MEC, Funarte/ Pró-Memus 3-56-404-007, Rio de Janeiro, 1979.

12. Oscar Guanabarino, "Artes e Artistas - Imprensa Musical", O Paiz, Rio de Janeiro, 28 out. 1895 (B.N. - S. Mc.) In Avelino Romero Simões Pereira, Música, Sociedade e Política: Alberto Nepomuceno e a República Musical do Rio de Janeiro, Dissertação: Mestrado em história. Rio de Janeiro, UFRJ, IFCS, 1995, p. 144. 
Pelas informações atuais, Alberto Nepomuceno não testemunhou a estréia de seus quartetos de cordas, em sua formação original. As razões para o aparente abandono não são muito claras e, sobre o fato de não se conhecer nenhuma referência em sua época, Sérgio Alvim Corrêa observa: "quanto aos quartetos, custa acreditar que tenham permanecido tanto tempo inéditos. Parece que o autor do Batuque os considerava meros ensaios experimentais, pois em vida nunca lhes fez qualquer menção"13. É provável que a imagem construída em função da postura panfletária de sua campanha pelo "canto brasileiro" tenha contribuído para o fato. Diversas frentes de batalha, como por exemplo as questões políticas ligadas à direção do Instituto Nacional de Música, parecem ter também exigido muito de suas energias. Somando-se ao fato de sua saúde necessitar, há muito, de cuidados especiais, sobrava pouco espaço para organizar audições de peças onde o autor não poderia atuar também como instrumentista pois, num ambiente musical como o do Rio de Janeiro do início do século XX, tudo indica que Nepomuceno teve êxito em fazer executar sua música apenas dentro da sua atuação como pianista, organista ou regente. Daí a utilização de alguns trechos dos quartetos apenas em formações orquestrais, conforme referimos anteriormente.

Como conclusão, apresentaremos nossa proposta de reformulação do catálogo para este conjunto específico das suas obras, elaborada a partir dos trabalhos de Sérgio Alvim Corrêa e Maria Alice Volpe:

\section{Quarteto de Cordas $\mathbf{n}^{\circ} \mathbf{1}$, em Si menor (para dois violinos, viola e violoncelo)}

Movimentos: Allegro agitato, em si menor, 4/4, $202 \mathrm{cp}$.

Andante, em lá maior, $3 / 4,85 \mathrm{cp}$.

Scherzo, em sol maior, $3 / 4,120 \mathrm{cp}$.

Allegro spirituoso, em ré maior, [2/4], $227 \mathrm{cp}$.

13. Sérgio Alvim Corrêa, op. cit., p. 1. 
Manuscrito autógrafo: pertencente à coleção particular de Sérgio Nepomuceno Alvim Corrêa, 36 p.

Local e data da composição: Roma, 1889 (na partitura manuscrita há também uma anotação posterior: 1890).

Primeira audição: 18.5.1933, Rio de Janeiro, no Instituto Nacional de Música; intérpretes: Quarteto Chiafitelli.

Discografia:

Documentos da Música Brasileira vol. 7. Música de Câmara do Brasil.

Rio de Janeiro, Funarte, LP: 356.404.007, 1979. Intérpretes: Quarteto de Cordas da Rádio MEC. Gravação re-editada pela série Acervo Funarte da Música Brasileira. São Paulo, Atração Fonográfica, CD: ATR 32028, 1998.

Alberto Nepomuceno (1864-1920): Edição Integral dos Quartetos de Cordas. São Paulo, Paulus, CD: 005007, 1999. Intérpretes: Quarteto Aureus.

\section{Quarteto de Cordas $n^{0}$ 2, em Sol menor (para dois violinos, viola e violoncelo)}

Movimentos: Allegro con fuoco, em sol menor, 4/4, $317 \mathrm{cp}$.

Andante espressivo, em dó maior, 3/4, $96 \mathrm{cp}$.

Scherzo, em ré menor, 3/4, $201 \mathrm{cp}$.

Finale: Allegro con fuoco, em sol menor, $3 / 4,315 \mathrm{cp}$.

Obs: existe uma versão para orquestra de cordas do $2^{\circ}$ movimento, o Andante espressivo, feita pelo compositor, onde foi apenas acrescentada a parte do contrabaixo. Esta versão isolada recebeu o mesmo título e foi estreada no dia 29 de fevereiro de 1902, em Petrópolis, RJ, no Club dos Diários, com a regência do compositor.

Manuscritos autógrafos: Partitura completa, pertencente à Biblioteca

Nacional - RJ, MS N-IV-40, 61 p. (indicação na página de rosto:

Op. 6 [riscado]).

Partitura completa, pertencente à Escola de Música - UFRJ, MS não processado, $31 \mathrm{p}$. 
Partitura incompleta, pertencente à coleção particular de Sérgio Nepomuceno Alvim Corrêa, 3 p.

Local e data da composição: Berlim, 1891.

Primeira audição: 2.5.1977, Missouri, EUA, no Fine Arts Recital Hall. Intérpretes: Quarteto Esterhazy.

Discografia:

Alberto Nepomuceno (1864-1920): Edição Integral dos Quartetos de Cordas. São Paulo, Paulus, CD: 005007, 1999. Intérpretes: Quarteto Aureus.

\section{Quarteto de Cordas $\mathbf{n}^{0} 3$, em Ré menor (para dois violinos, viola e violoncelo)}

Movimentos: Allegro moderato, em ré menor, 3/4, $251 \mathrm{cp}$.

Andante, em sol menor, 4/4, $168 \mathrm{cp}$.

Intermezzo: allegretto, em lá maior, $2 / 4,169 \mathrm{cp}$.

Allegretto, em sol maior, 3/8, $196 \mathrm{cp}$.

Obs: o terceiro movimento recebeu do compositor uma versão para orquestra sinfônica e foi incluído na sua mais famosa suíte orquestral, a Série Brasileira (1891), recebendo o nome de Intermédio.

Manuscrito autógrafo: partitura completa, pertencente à Biblioteca Nacional - RJ, MS N-IV-34, 41 p.

Local e data da composição: Berlim, 1891.

Primeira audição: 26.4.1962, São Paulo, na Sociedade Pró-Música Brasileira. Intérpretes: Quarteto Municipal de São Paulo. A estréia foi precedida de uma primeira execução radiofônica: 5.9.1960, Rio de Janeiro, na Rádio MEC, programa Música e Músicos do Brasil. Intérpretes: Quarteto da Rádio MEC.

Discografia: 
Documentos da Música Brasileira vol. 7. Música de Câmara do Brasil. Rio de Janeiro, Funarte, LP: 356.404.007, 1979. Intérpretes: Quarteto de Cordas da Rádio MEC. Gravação re-editada pela série Acervo Funarte da Música Brasileira. São Paulo, Atração Fonográfica, CD: ATR 32028, 1998.

CBS (Columbia) / Odyssey. Intérpretes: Quarteto Oficial da ENM - RJ, LP: 9093 / 32160176, 1970. Gravação re-editada pela Fundação Universitária José Bonifácio, Rio de Janeiro, CD: FDA198, 1999.

Uma homenagem a Mário de Andrade. São Paulo, CHASE - Concept \& Idea, CD: CPI 1.0010, 1992. Intérpretes: Quarteto de Cordas da Cidade de São Paulo.

Alberto Nepomuceno (1864-1920): Edição Integral dos Quartetos de Cordas. São Paulo, Paulus, CD: 005007, 1999. Intérpretes: Quarteto Aureus. 